\title{
Ankylosing Spondylitis: Patterns of Spinal Injury and Treatment Outcomes
}

\author{
Idiris Altun, Kasım Zafer Yuksel \\ Neurosurgery Department, Medical Faculty, Kahramanmaraş Sütcü Imam University, Kahramanmaras, Turkey
}

\section{Study Design: Retrospective review.}

Purpose: We retrospectively reviewed our patients with ankylosing spondylitis (AS) to identify their patterns of spinal fractures to help clarify management strategies and the morbidity and mortality rates associated with this group of patients.

Overview of Literature: Because of the brittleness of bone and long autofused spinal segments in AS, spinal fractures are common even after minor trauma and often associated with overt instability.

Methods: Between January 1, 1998 and March 2011, 30 patients (23 males, 7 females; mean age, 70.43 years; range, 45 to 95 years) with the radiographic diagnosis of AS of the spinal column had 42 fractures. Eight patients presented with significant trauma, 17 after falls, and 5 after minor falls or no recorded trauma. Eleven patients presented with a neurological injury, ranging from mild sensory loss to quadriplegia.

Results: There were 16 compression and 10 transverse fractures, two Jefferson's fractures, one type II and two type III odontoid process fractures, and five fractures of the posterior spinal elements (including lamina and/or facet, three spinous process fractures, three transverse process fractures). Twenty-four fractures affected the craniocervical junction and/or cervical vertebrae, 17 were thoracic, and one involved the lumbar spine. The most affected vertebrae were C6 and T10. The mean follow-up was 29.9 months. One patient was lost to follow-up. Eighteen patients were treated conservatively with bed rest and bracing. Twelve patients underwent surgery for spinal stabilization either with an anterior, posterior or combined approach.

Conclusions: Nonsurgical treatment can be considered especially in the elderly patients with AS and spinal trauma but without instability or major neurological deficits. The nonfusion rate in conservatively treated patients is low. When treatment is selected for patients with spinal fractures and AS, the pattern of injury must be considered and the need for individualized treatment is paramount.

Keywords: Ankylosing spondylitis; Treatment; Magnetic resonance imaging; Low back pain; Epidemiology

\section{Introduction}

First described by Marie in 1897 and by Strumpell in 1898, ankylosing spondylitis (AS) is a chronic inflammatory condition [1]. The disease is characterized by calcification of the intervertebral discs and ossification of the ligaments with ankylosis of the apophyseal joints. The re- sult is immobility and generalized osteoporosis that affect axial joints and bones with a reported prevalence of $0.02 \%$ to $0.23 \%$ [2-4].

Fractures of the ankylosed spine are common due to a given patient's progressive loss of mobility and secondary osteoporosis. Fractures are a serious complication of AS [5], and patients are prone to spinal injuries, even with

Received Dec 10, 2015; Revised Jan 1, 2016; Accepted Jan 2, 2016

Corresponding author: Idiris Altun

Neurosurgery Department, Kahramanmaraş Sütçü İmam Üniversitesi, Tip Fakültesi Hastanesi,

Beyin Ve Sinir Cerrahisi Servisi, Kahramanmaraş, Turkey

Tel: +90-344-280-3398, Fax: +90-344-280-4042, E-mail: idrisaltun46@hotmail.com 
minor trauma or no trauma at all [1,6-9]. A history of chronic neck and back pain before the injury can cause such fractures to be overlooked. In patients with AS, difficulties related to the radiological assessment of the spine as a result of their osteoporosis can further mask the diagnosis. In some cases, ossified disc spaces may be poorly outlined $[7,10,11]$.

Treatment and rehabilitation of these patients are challenging. Furthermore, some aspects of their treatment differ from those of individuals with spinal fractures but without AS $[6,7,12]$. We retrospectively reviewed our patients with AS in order to identify their patterns of spinal fractures, to help clarify management strategies, and to assess the morbidity and mortality rates associated with this group of patients.

\section{Materials and Methods}

The medical reports of patients with diagnosis of AS and cervical, thoracic or lumbar fractures treated between

Table 1. Clinical summary of 30 patients with AS and spinal fractures

\begin{tabular}{|c|c|c|c|c|}
\hline Patient & Age/sex & Injury level & Pathology & Fracture mechanism \\
\hline 1 & 61/Male & C6-7 & Frx+dislocation & Ground fall \\
\hline 2 & 78/Male & L5-S1 & Transverse & Ground fall \\
\hline 3 & 61/Male & C6-7 & Frx+dislocation & Trampetine fall \\
\hline 4 & 70/Male & T9 Corpus & Pseudoarthrozis & Ground fall \\
\hline 5 & 75/Male & T8 Corpus & Corpus Frx & Motor vehicle accidents \\
\hline 6 & 60/Female & $\mathrm{C} 1$ & Jefferson Frx & Ground fall \\
\hline 7 & 67/Male & T8 & Burst & Preexisting lymphoma no trauma \\
\hline 8 & 87/Male & C5 & Transverse & No trauma (X-ray for pain) \\
\hline 9 & 52/Male & $\mathrm{C7}$ & Compression & Ground fall \\
\hline 10 & 63/Male & $\mathrm{C} 1+\mathrm{C} 3-4$ & Jefferson+C3-4 Frx dislocation & Level 1 trauma \\
\hline 11 & 49/Male & $\mathrm{T} 1,2,3,4,5,6,8$ & T8 compression others spinous proc & Fall \\
\hline 12 & 66/Female & T5 & Chance (Sup T5 Corpus) & Fall \\
\hline 13 & 45/Male & Odontoid & Type 3 & Motor vehicle accidents \\
\hline 14 & 71/Male & Odontoid & Type 3 & Motor vehicle accidents \\
\hline 15 & 74/Male & C6-7 & Transvers & Fall \\
\hline 16 & 79/Male & C5-6 & Frx+dislocation & Fall \\
\hline 17 & 85/Female & $\mathrm{T} 10, \mathrm{~T} 11$ & T10 compression T11 transvers & Fall \\
\hline 18 & 66/Female & C4 T3 & Minimal compression & Fall \\
\hline 19 & 80/Female & C6-7 & Transvers & Motor vehicle accidents \\
\hline 20 & 53/Male & $\mathrm{T7}, \mathrm{T} 10$ & Minimal compression & Trauma \\
\hline 21 & 73/Male & $\mathrm{C7}$ & Kompression & Fall \\
\hline 22 & 88/Female & C6-7 & Transvers & Incidentally \\
\hline 23 & 88/Female & $\mathrm{C5}$ & Corpus Frx & Ground fall \\
\hline 24 & 93/Male & $\mathrm{T} 12$ & Body Frx & Fall \\
\hline 25 & 81/Male & C6-7 & Transvers & No trauma myelopathy signs \\
\hline 26 & 57/Male & $\mathrm{C6}, \mathrm{C7}$ & C6 left transvers proc C7 right lamina & Trauma \\
\hline 27 & 57/Male & C6 & Left transvers process & No trauma \\
\hline 28 & 95/Male & $\mathrm{T} 1$ & Compression & Fall \\
\hline 29 & 85/Male & $\mathrm{T} 10$ & Transvers & Fall \\
\hline 30 & 54/Male & T10-11 & Transvers & Motor vehicle accidents \\
\hline
\end{tabular}

AS, ankylosing spondylitis; Frx, fractures. 
January 1, 1998 and March 2011 at our institution were reviewed retrospectively. Thirty patients (23 men and 7 women, mean age at injury 70.4 years; age range, 45-95 years) with complete clinical, radiological, and neuroimaging data were included in the study (Table 1 ).

AS was diagnosed by plain radiography of the spine in all patients. Seventeen patients were evaluated with computerized tomography (CT) of the spine. One patient had also undergone myelography and postmyelography CT. The remaining 13 patients, most of whom had neurological deficits, underwent magnetic resonance imaging (MRI) at their first hospital admission for the suspicion of spinal trauma. Follow-up examinations included plain radiography, CT, MRI, or combinations of these modalities relevant to the pathology treated (Figs. 1-4).

Eight patients had sustained significant trauma (mean age 66.1 years) as a result of motor vehicle accidents (MVA) or assaults. Seventeen patients (mean age, 69.1 years) had suffered falls-11 from a height and 6 from the ground level. Five patients had experienced only mi-
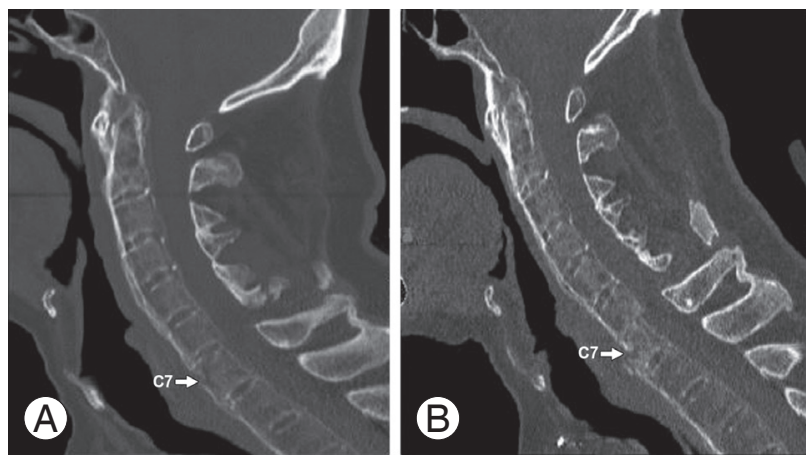

Fig. 1. (A, B) Sagittal computed tomography of C7 fracture (arrows).
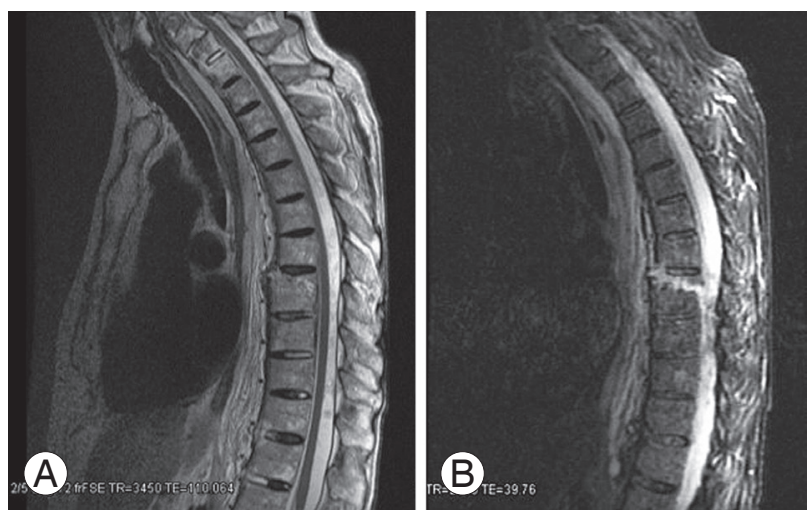

Fig. 2. (A) Sagittal T2-weighted and (B) sagittal short T1 inversion recovery magnetic resonance imaging. nor trauma or had no trauma (mean age, 76 years; range, 57-88 years) (Table 1 ).

Surgical management was based on presence of instability and progressive neurological deficits, especially when no medical contraindications were present. Patients underwent posterior fusion, anterior decompression, or both. Instrumentation included pedicle screws, C1-2 transarticular screws, lateral mass screws, hooks, or combination of these constructs. Patients requiring anterior decompression also were fused with a graft or cages and plates. Conservative treatment consisted of bed rest for up to 1 week followed by gradual mobilization in a halo, thoracolumbosacral orthosis, or hard collar. External immobilization was continued until the fusion was evident on radiological studies (mean, 5.7 months) (Table 2).

The length of follow-up was calculated from the date of admission to the patients' most recent evaluation. Modified Frankel scores of all patients determined at admission and at all follow-up examinations were used as the measure of neurological status and clinical outcome [7].
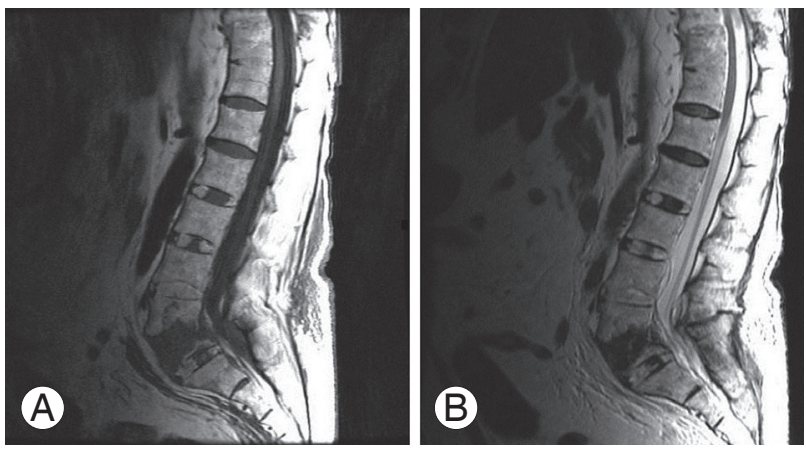

Fig. 3. (A) Sagittal T1-weighted and (B) T2-weighted magnetic resonance imaging of $L 5$ fracture.
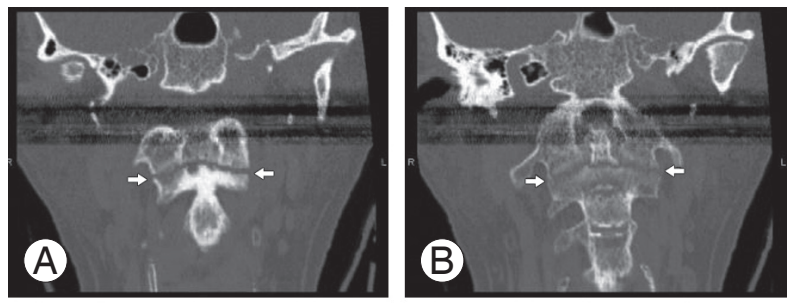

Fig. 4. Sequence of $(\mathbf{A}-\mathrm{C})$ coronal computed tomography scans showing the odontoid fractures (arrows).

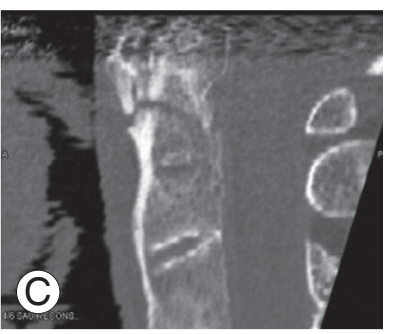


Table 2. Treatment summary of 30 patients with ankylosing spondylitis and spinal fractures

\begin{tabular}{|c|c|c|c|c|c|c|}
\hline Patient & Fusion & Laminectomy & Anterior surgery & Posterior surgery & Combined & Conservative \\
\hline 1 & Yes & No & No & No & No & $\begin{array}{l}\text { Halo7 months then } \\
\text { Miami J Collar }\end{array}$ \\
\hline 2 & No & No & No & L4-S1 pedicle screw fixation & No & No \\
\hline 3 & No & Yes & No & $\begin{array}{c}\text { C5, 6, } 7 \text { laminectomy } \\
\text { C4-T2 lat mass+pedicul screw }\end{array}$ & No & No \\
\hline 4 & No & No & No & No & No & $\begin{array}{c}\text { Thoracolumbosacral } \\
\text { orthosis }\end{array}$ \\
\hline 5 & Yes & No & Yes partial corpectomy & Yes pedicle screw & Yes & No \\
\hline 6 & No & No & No & No & No & Hard collar \\
\hline 7 & Yes & No & $\begin{array}{l}\text { T8 corpectomy } \\
\text { cage }\end{array}$ & $\begin{array}{l}\text { T6,7 Hook-T9,10 pedicle } \\
\text { screw fixation }\end{array}$ & Yes & No \\
\hline 8 & No & No & No & No & No & Halo \\
\hline 9 & No & No & No & No & No & Halo \\
\hline 10 & No & No & No & No & No & Halo \\
\hline 11 & Yes & Yes & No & Yes pedicle screw (T6-12) & No & No \\
\hline 12 & No & No & No & No & No & $\begin{array}{c}\text { Thoracolumbosacral } \\
\text { orthosis }\end{array}$ \\
\hline 13 & Yes & No & No & Yes C1-2 & No & No \\
\hline 14 & Yes & No & No & Yes C1-2 & No & No \\
\hline 15 & No & No & No & No & No & Halo \\
\hline 16 & Yes & No & $\begin{array}{l}\text { Yes ant partial } \\
\text { corpectomy+plate }\end{array}$ & No & No & No \\
\hline 17 & Yes & Yes & No & Yes & No & No \\
\hline 18 & No & No & No & No & No & Hard Collar \\
\hline 19 & No & No & No & No & No & Halo \\
\hline 20 & No & No & No & No & No & Recumbency \\
\hline 21 & Yes & No & $\begin{array}{c}\text { Yes C6-T1 } \\
\text { decompression }\end{array}$ & No & No & No \\
\hline 22 & No & No & No & No & No & Halo \\
\hline 23 & No & No & No & No & No & Collar recumbency \\
\hline 24 & No & No & No & No & No & $\begin{array}{c}\text { Thoracolumbosacral } \\
\text { orthosis }\end{array}$ \\
\hline 25 & Yes & No & $\begin{array}{l}\text { Yes C7 corpectomy } \\
\text { C5-T1 fusion }\end{array}$ & No & No & No \\
\hline 26 & No & No & No & No & No & Collar recumbency \\
\hline 27 & No & No & No & No & No & Collar recumbency \\
\hline 28 & No & No & No & No & No & Collar recumbency \\
\hline 29 & No & No & No & No & No & $\begin{array}{c}\text { Thoracolumbosacral } \\
\text { orthosis }\end{array}$ \\
\hline 30 & Yes & No & Hemicorpectomy & T12-L1 pedicle screw fusion & Yes & No \\
\hline
\end{tabular}

\section{Results}

The mean follow-up was 29.9 months (Table 3).

\section{Mechanism of injury and fracture pattern}

The primary mechanism of injury in our patients with 
Table 3. Frankel scores of patients

\begin{tabular}{|c|c|c|c|c|}
\hline Patient & Admission Frankel score & Follow-up Frankel score & Follow-up (mo) & Prior fractures \\
\hline 1 & 5 & 5 & 10 & No \\
\hline 2 & 4 & 5 & 11 & Left transvers process of $L 4$ \\
\hline 3 & 5 & 5 & 8 & No \\
\hline 4 & 5 & 5 & 21 & No \\
\hline 5 & 1 & 1 & 13 & No \\
\hline 6 & 5 & 5 & 16 & No \\
\hline 7 & 4 & 4 & 9 & No \\
\hline 8 & 5 & 5 & 2 & No \\
\hline 9 & 5 & 5 & 5 & C4, C5 spinous process fractures \\
\hline 10 & 1 & Exitus & No & No \\
\hline 11 & 4 & 5 & 11 & No \\
\hline 12 & 5 & 5 & 13 & No \\
\hline 13 & 4 & 4 & 7 & T8 old compression \\
\hline 14 & 3 & 3 & 24 & No \\
\hline 15 & 5 & 5 & 36 & No \\
\hline 16 & 4 & 5 & 28 & No \\
\hline 17 & 1 & 1 & 4 & No \\
\hline 18 & 5 & 5 & 48 & No \\
\hline 19 & 5 & 5 & 14 & No \\
\hline 20 & 5 & 5 & 60 & Rib fractures \\
\hline 21 & 5 & 5 & 30 & No \\
\hline 22 & 4 & 4 & 24 & C1-2 subluxation old \\
\hline 23 & 5 & 5 & 2 & No \\
\hline 24 & 5 & 5 & 19 & No \\
\hline 25 & 5 & 5 & 19 & No \\
\hline 26 & 5 & 5 & 34 & No \\
\hline 27 & 5 & 5 & 14 & No \\
\hline 28 & 5 & 5 & 12 & No \\
\hline 29 & 5 & 5 & 13 & No \\
\hline 30 & 4 & 5 & 21 & No \\
\hline
\end{tabular}

spinal fractures and AS was falls (17 cases). Six of these cases were ground level falls and included falls from a standing position. The other 11 patients had major falls, including falls from heights, during bed transfers, or from a trampoline (Table 1).

In all patients who had fallen, the thoracic region was most often affected (8 patients) followed by the cervical region (7 patients) and lumbar region (1 patient). One patient had both cervical and thoracic compression fractures. When the mechanism of injury was a low-magnitude force, such as a ground level fall, there were 4 cervi- cal fractures, 1 thoracic fracture, and 1 lumbar fracture (Table 1).

For the 8 cases that had sustained a major trauma from a MVA or assault, cervical fractures were prominent (6 patients). Of the 5 patients who did not mention experiencing a trauma or had a history of minor trauma such as lifting a heavy object, fractures were detected by radiological investigation performed for back pain or neurological symptoms. Four of these patients had a cervical fracture and one had a thoracic fracture (Table 1). 


\section{Presentation fracture patterns}

Altogether, 42 fractures were observed in 30 patients. Nine patients had suffered from multiple spinal fractures (multiple fractures involved at the same segment of the spine in 8 patients and involved the cervical and thoracic regions in one patient (Table 1 ).

In 10 transverse fractures, the fracture line extended through the entire bone or disc space either through the vertebral body or ossified ligaments. This fracture pattern is often encountered in patients with AS and can include all three spinal columns. There were 16 compression fractures, 2 Jefferson's fractures, 1 type II and 2 type III odontoid process fractures, 5 lamina and/or facet fractures, 3 spinous process fractures, and 3 transverse process fractures. Twenty-four fractures affected the craniocervical junction, cervical vertebrae, or both. Seventeen affected the thoracic spine, and 1 affected the lumbar spine (Fig. 5). The vertebrae most often involved were C6-T10. Radiological investigation of 4 patients also showed an old fracture of the lumbar transverse process, 2 old fractures of the cervical spinous processes, and 1 old thoracic compression fracture. One patient also had multiple old rib fractures (Table 1).

\section{Neurological status}

The mean modified Frankel score was 4.3 at admission and 4.5 at the last follow-up examination. Based on modified Frankel scores, 19 patients had no neurological deficits at admission and remained stable throughout their course: 13 had fallen (5 from ground level), 3 had no history of trauma, and 3 patients had sustained major trauma. Eleven patients presented with neurological injury, ranging from mild sensory loss to quadriplegia. Of these patients with modified Frankel scores of 4, there were 4 who exhibited a 1-point improvement in their modified Frankel scores with treatment during their follow-up (Table 3). Three patients had major neurological deficits (modified Frankel score 3 or less) - two had been in an MVA and one had fallen from a height. Their deficits failed to improve after treatment.

\section{Treatment}

Eighteen patients were treated conservatively, 16 of whom had a modified Frankel score of 5 at admission and stable vertebral colon. One patient with a modified Frankel score of 4 and one patient with a score of 1 did not undergo surgery and were treated only with an external orthosis

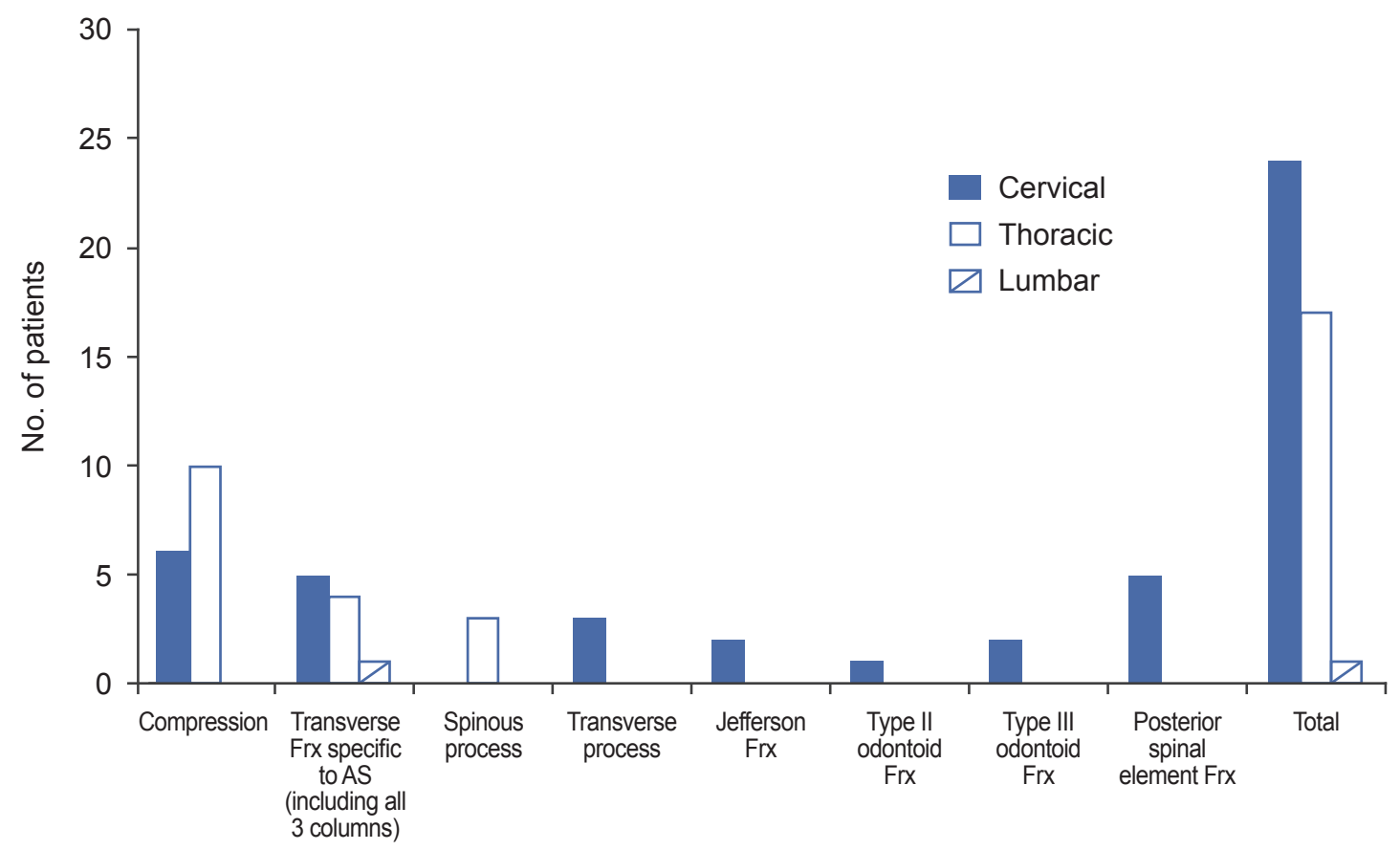

Fig. 5. The distribution of types of pathology in patients. AS, ankylosing spondylitis; Frx, fractures. 
because complicating medical factors precluded surgery. One patient who was treated conservatively developed skin ulcers under the halo brace. One conservatively treated patient who exhibited non-fusion died.

Twelve patients underwent 15 surgical procedures: 9 posterior, 6 anterior, and 3 combined approaches for spinal stabilization. The complications in the surgical group were loss of reduction and pseudarthrosis in one patient, requiring re-operation, a wound infection in another patient, and one mortality because of pneumonia. Our morbidity rate was $6.7 \%$ and for mortality, it was 3.3\% (Table 2).

\section{Discussion}

Compared to the healthy general population, the risk of AS patients sustaining a vertebral fracture is significantly increased. In patients with AS who have sustained fractures, the rate of neurological deficits has ranged from $40 \%$ to $92 \%$ [1,5,7,10,12-15]. In our series the incidence of neurological deficits was $37 \%$, a relatively low rate that may be related to several factors. First, patient transportation after injury has improved considerably. Early medical care, even after minor trauma or in patients with pain without trauma, helps avoid major injuries by promoting early diagnosis and treatment. The number of missed fractures, which can be devastating in AS patients, has also decreased as neuroradiological imaging techniques have improved. Likewise, the quality of education for AS patients about their disease and related spinal complications is better, as preventive measures may help patients avoid spinal trauma or lessen its impact. Awareness of their spinal fragility with how to avoid situations that increase the risk of spinal injury and how to alleviate the effect of forces in an accident can all help reduce the incidence of fractures and concomitant neurological deficits in this population.

From previous studies, the predominant site for spinal fractures in AS patients has been the lower cervical spine [1]. Olerud et al. [6] reviewed 31 AS patients with spinal fractures; these included 19 cervical fractures with 5 that involved $\mathrm{C} 1-\mathrm{C} 2$ and 14 the subaxial spine. Graham and Van Peteghem [12] reported that 12 of their 15 cases sustained cervical fractures. Fox et al. [13] performed 41 operations in AS patients: 17 for cervical, 14 for thoracic, and 10 for lumbar fractures.13 In our series, most fractures also involved the cervical spine. In patients who had falls, however, the thoracic region was most often affected.
Compared with other series, our patients were older. The known increases in kyphosis related to AS and osteoporosis with advanced age may have predisposed our patients who fell to thoracic fractures. We believe that older AS patients with even an ambiguous medical history related to falls should be evaluated in detail for thoracic fractures. Recent studies have focused on the clinical outcomes of patients with AS and cervical or thoracolumbar fractures involving one spinal segment $[5,14,16,17]$. New clinical series with large number of AS patients and wide age ranges and devoted to evaluating the entire spine are needed to understand fracture locations in different age groups.

In AS patients, the mechanism of injury underlying most spinal fractures is a small-magnitude force $[1,6,12,18]$. Some fractures are diagnosed incidentally when investigating other complaints, and some fractures are unrelated to trauma $[7,19]$. Occult vertebral fractures are also common in patients with AS [10]. Five of our patients had no history of trauma while six patients had only experienced ground level falls. These findings are consistent with other reports of the importance of minor trauma as a cause of spinal fractures in AS patients. In this context, clinicians must be mindful of a high likelihood of spinal fractures in patients with AS.

The primary pattern of injury in our AS patients was falls, and the mean age of these patients was high relative to other reports. Along with an inherent increase in kyphosis, changes in the biomechanical properties of the spine, shifts in the center of gravity acting on the body, and geriatric problems such as widespread arthrosis and coordination problems can all contribute to this pattern of injury. Consequently, such patients should be cautioned about falls. If necessary, they should be advised to use mobility-related assistive technology such as walkers, wheelchairs, or canes.

The ideal treatment for spinal fractures in AS is controversial $[4,12]$. Furthermore, it is difficult to apply fracture classification systems developed for normal spines to patients with AS because their fracture lines usually extend through the entire bone. During extension or flexion, this type of fracture is like the fracture of a long bone [6]. Consequently, it is challenging to identify spinal instability. Decisions must be based on patient's individual characteristics and findings. The surgical treatment of these patients is associated with high complication and mortality rates, especially in older patients, and neurological improvement is minimal $[6,12,20]$. Graham and Van 
Peteghem [12] also reported a high rate of fracture union and a low rate of morbidity and mortality in patients treated conservatively. We treated 18 patients conservatively. Although these patients were relatively aged (mean, 71.1) having other complicating medical situations as well, only one case of pseudarthrosis was encountered.

For our study, the weak points were the lack of data on severity of AS, the degree of osteoporosis and fusion rates of fractures.

\section{Conclusions}

In conclusion, nonsurgical treatment can be considered as the first step of treatment, especially in elderly patients with AS and spinal trauma but without instability or major neurological deficits. The nonfusion rate in conservatively treated patients is low. When treatment is selected for patients with spinal fractures and AS, the pattern of injury must be considered and the need for individualized treatment is paramount.

\section{Conflict of Interest}

No potential conflict of interest relevant to this article was reported.

\section{References}

1. Westerveld LA, Verlaan JJ, Oner FC. Spinal fractures in patients with ankylosing spinal disorders: a systematic review of the literature on treatment, neurological status and complications. Eur Spine J 2009;18: 145-56.

2. Bennett GJ. Ankylosing spondylitis. Clin Neurosurg 1991;37:622-35.

3. Braun J, Sieper J. Ankylosing spondylitis. Lancet 2007;369:1379-90.

4. Yilmazlar S, Kocaeli H, Doygun M. Chance type cervical fracture and neurological deficits in ankylosing spondylitis. Ulus Travma Acil Cerrahi Derg 2003; 9:76-8.

5. Hitchon PW, From AM, Brenton MD, Glaser JA, Torner JC. Fractures of the thoracolumbar spine complicating ankylosing spondylitis. J Neurosurg 2002;97(2 Suppl):218-22.

6. Olerud C, Frost A, Bring J. Spinal fractures in patients with ankylosing spondylitis. Eur Spine J 1996;5: 51-5.
7. Sapkas G, Kateros K, Papadakis SA, et al. Surgical outcome after spinal fractures in patients with ankylosing spondylitis. BMC Musculoskelet Disord 2009; 10:96.

8. Schroder J, Liljenqvist U, Greiner C, Wassmann H. Complications of halo treatment for cervical spine injuries in patients with ankylosing spondylitis: report of three cases. Arch Orthop Trauma Surg 2003;123:112-4.

9. Whang PG, Goldberg G, Lawrence JP, et al. The management of spinal injuries in patients with ankylosing spondylitis or diffuse idiopathic skeletal hyperostosis: a comparison of treatment methods and clinical outcomes. J Spinal Disord Tech 2009;22:77-85.

10. Finkelstein JA, Chapman JR, Mirza S. Occult vertebral fractures in ankylosing spondylitis. Spinal Cord 1999;37:444-7.

11. Trent G, Armstrong GW, O'Neil J. Thoracolumbar fractures in ankylosing spondylitis: high-risk injuries. Clin Orthop Relat Res 1988;227:61-6.

12. Graham B, Van Peteghem PK. Fractures of the spine in ankylosing spondylitis: diagnosis, treatment, and complications. Spine (Phila Pa 1976) 1989;14:803-7.

13. Fox MW, Onofrio BM, Kilgore JE. Neurological complications of ankylosing spondylitis. J Neurosurg 1993;78:871-8.

14. Taggard DA, Traynelis VC. Management of cervical spinal fractures in ankylosing spondylitis with posterior fixation. Spine (Phila Pa 1976) 2000;25:2035-9.

15. Weinstein PR, Karpman RR, Gall EP, Pitt M. Spinal cord injury, spinal fracture, and spinal stenosis in ankylosing spondylitis. J Neurosurg 1982;57:609-16.

16. Nakstad PH, Server A, Josefsen R. Traumatic cervical injuries in ankylosing spondylitis. Acta Radiol 2004; 45:222-6.

17. Pedrosa I, Jorquera M, Mendez R, Cabeza B. Cervical spine fractures in ankylosing spondylitis: MR findings. Emerg Radiol 2002;9:38-42.

18. Murray GC, Persellin RH. Cervical fracture complicating ankylosing spondylitis: a report of eight cases and review of the literature. Am J Med 1981;70:1033-41.

19. Good AE. Nontraumatic fracture of the thoracic spine in ankylosing spondylitis. Arthritis Rheum 1967;10:467-9.

20. Hunter T, Dubo HI. Spinal fractures complicating ankylosing spondylitis: a long-term followup study. Arthritis Rheum 1983;26:751-9. 